\title{
BMJ Open Health policies on dialysis modality selection: a nationwide population cohort study
}

\author{
Yi-Chun Lin, ${ }^{1,2}$ Yen-Chung Lin, ${ }^{3,4}$ Chih-Chin Kao, ${ }^{3,4}$ Hsi-Hsien Chen, ${ }^{3,4}$ \\ Chih-Cheng Hsu, ${ }^{5}$ Mai-Szu Wu ${ }^{3,4}$
}

To cite: Lin Y-C, Lin Y-C, Kao C-C, et al. Health policies on dialysis modality selection: a nationwide population cohort study. BMJ Open 2017;7:e013007. doi:10.1136/bmjopen-2016013007

\section{- Prepublication history for this paper is available online. To view these files please visit the journal online (http://dx.doi.org/10.1136/ bmjopen-2016-013007). \\ Received 13 June 2016 Revised 20 October 2016 Accepted 16 December 2016



${ }^{1}$ Division of Endocrinology \& Metabolism, Department of Medicine, Taipei Veterans General Hospital, Taipei, Taiwan

${ }^{2}$ Faculty of Medicine, National Yang-Ming University, Taipei, Taiwan

${ }^{3}$ Division of Nephrology, Department of Internal Medicine, Taipei Medical University Hospital, Taipei, Taiwan

${ }^{4}$ Department of Internal Medicine, School of Medicine, College of Medicine, Taipei Medical University, Taipei, Taiwan ${ }^{5}$ Institute of Population Health Sciences, National Health Research Institutes, Zhunan, Taiwan

\section{Correspondence to} Dr Mai-Szu Wu; maiszuwu@gmail.com or Dr Yen-Chung Lin; yclin0229@tmu.edu.tw

\section{ABSTRACT}

Objectives: In Taiwan, peritoneal dialysis (PD) and haemodialysis are fully accessible to patients with endstage renal disease. However, the usage of PD is considered low in Taiwan. Since 2005, 4 major policies have been implemented by Taiwan's Ministry of Health and Welfare, namely a multidisciplinary predialysis care programme and usage increasing the PD incidence as a key performance indicator (KPI) for hospital accreditation, both of which were implemented in 2006; reimbursement of the glucose-free dialysate, icodextrin that was implemented in 2007; and insurance reimbursement for renting automated PD machines that was implemented in 2008. The aim of this study was to analyse the associations between the PD promotional policies and the actual PD selection rates.

Setting: We analysed data within the Taiwan Renal Registry Data System from 2006 to 2013, focusing on the PD incidence in relation to the timings of the $4 \mathrm{PD}$ promotional policies; then we stratified the results according to age, sex and the presence of diabetes mellitus.

Participants: From 2006 to 2013, 115565 patients were enrolled in this study. The mean (SD) age of patients on PD was 54.6 (15.7) years.

Results: During the time frame in which the $4 \mathrm{PD}$ promotional policies were implemented, the PD incidence increased from $12.8 \%$ in 2006 to $15.1 \%$ in 2009. The PD incidence started to decline in 2010 $(13.8 \%)$ when the hospital accreditation policy was repealed. The 3 remaining policies were weakly associated with the PD incidence. The observational analysis determined that the patients' ages, sexes and diabetes mellitus incidence rates were relatively stable from 2006 to 2013.

Conclusions: Of the 4 health policies intended to promote PD usage, using increasing the PD incidence as a KPI for hospital accreditation had the strongest association with the PD incidence.

\section{INTRODUCTION}

The increasing number of people with endstage renal disease (ESRD) is placing a considerable burden on the Taiwanese government.

\section{Strengths and limitations of this study}

- This study was based on a comprehensive longterm, nationwide, population-based end-stage renal disease registry system.

- Four health policies and the incidence of peritoneal dialysis (PD) according to the timings of their implementation were presented in this study.

- The temporal associations between the four health policies and the PD incidence did not prove causation.

- Unmeasured confounding factors, for example, a physician's experience or preference, may exist.

- A lack of valid kidney transplant records in this database was observed.

According to the US Renal Data System (USRDS) annual report, ${ }^{1}$ Taiwan had the highest prevalence and incidence of ESRD compared with other countries. The health expenditure for patients with ESRD comprised $6 \%$ of Taiwan's total annual National Health Insurance (NHI) budget, and it benefited $0.3 \%$ of the Taiwanese population who underwent advanced renal replacement therapy (RRT) by receiving either haemodialysis (HD) or peritoneal dialysis (PD).

In Taiwan, HD was first administered in 1963 and PD was first administered in 1984. The Taiwanese government has provided global coverage of the dialysis costs for every citizen since 1995. At present, the numbers of $\mathrm{HD}$ and PD facilities are sufficient to provide quality dialysis to patients with ESRD in Taiwan. The monthly reimbursements to physicians and the insurance payments to healthcare institutions are similar for patients on HD and PD in Taiwan. Eligible patients can select the dialysis modality they wish to receive. The usage of $\mathrm{PD}$ remained at $<10 \%$ in 2005, and inadequate patient education was considered to underlie this low usage rate because, in the context of patientcentred care, it is essential that patients with 
ESRD are aware of all the RRT modalities that are available. Several therapy barriers, including peritoneal membrane longevity and hypoalbuminaemia, are encountered while PD is administered, which necessitates the implementation of favourable healthcare policies $^{2}{ }^{3}$ and integrated health resources to increase the usage of $\mathrm{PD}{ }^{4}$

Administrative interventions, for example, the 'PD first' policies in Thailand ${ }^{5}$ and Hong Kong, ${ }^{6} 7$ have greatly influenced medical practice. ${ }^{8}$ Over the past three decades, a dialysis reimbursement policy has helped to provide sufficient incentives for PD selection. ${ }^{7}$ In Taiwan, four policies proposed by the Ministry of Health and Welfare relating to modality selection were implemented to increase the incidence of patients receiving PD as their initial RRT. In 2006, a multidisciplinary predialysis care programme was implemented in healthcare institutions that provided patients with chronic kidney disease (CKD) with more medical information about PD. Additionally, in 2006, increasing the PD incidence became a key performance indicator (KPI) for hospital accreditation. Reimbursements of glucose-free dialysate, icodextrin from the Bureau of NHI for patients on PD with increased levels of transport of low-molecular weight solutes across the peritoneal membrane or refractory oedema were implemented in 2007 , thereby providing incentives for nephrologists and hospitals to relieve patients' fluid retention and ultrafiltration failures. In 2008, insurance reimbursements for renting automated PD (APD) machines were implemented, thereby ensuring greater patient satisfaction and convenience in relation to PD. These policy provisions therefore included patient education, accreditation and incentives to encourage patients to select a particular RRT modality. The aim of this study was to analyse the temporal relationships between the PD promotional policies and the actual PD selection rates.

\section{METHODS}

\section{Ethical considerations}

This study was carried out in accordance with the principles of the 2013 revision of the Declaration of Helsinki 1975. ${ }^{9}$ Taipei Medical University's Institutional Review Board waived the requirement to obtain informed consent, because the study met all of the applicable regulations.

\section{Taiwan Renal Registry Data System}

The Taiwan Renal Registry Data System (TWRDS) was initially established in 1987 for the accreditation of dialysis therapy, as previously described. All dialysis units in Taiwan are obliged to upload relevant data to the website that was constructed by the TWRDS in 2005 . This provided only a very small portion of the incentives (5\%) to the dialysis centres and there were no corrections with the medical reimbursements for overall expenditure from the Bureau of NHI. Each dialysis unit submits a quarterly report that is prepared by a specially registered nurse. The data within the TWRDS provide a solid foundation for continual dialysis quality control at a national level. ${ }^{10-13}$ From 2006 to 2008, four major administrative or incentive-based interventions were implemented to influence dialysis modality selection, and policy implementation was measured by the Taiwan Society of Nephrology (TSN) under the surveillance of the Ministry of Health and Welfare.

\section{Patient enrolment}

Data submitted to the TWRDS in annual and quarterly reports were extracted for this study.

Patients who were registered with the TWRDS from 2006 to 2013 were included in the analysis $(n=115565)$, and those who had received HD or PD for $>3$ months were assigned to the HD or the PD group, respectively. After excluding 4661 patients who changed their dialysis modality, the final sample for the analysis comprised 110994 patients. Of these patients, 101672 (91.6\%) patients had selected HD and $9232(8.3 \%)$ patients had selected PD as their initial RRT modality between 2006 and 2013. Given that there is only one Bureau of NHI in Taiwan and that its coverage is nearly $99.6 \%$, patients on dialysis who did not attend follow-up assessments were considered deceased. Patients with uraemia who were no longer registered with the TWRDS were also considered deceased, and this was based on the total NHI coverage policy for all RRT expenditures. In addition, the kidney transplantation rate was 300 cases per year.

\section{Health policies}

\section{Multidisciplinary predialysis care programme}

The multidisciplinary predialysis care programme was designed and managed by the TSN. ${ }^{14}$ Since 2003, this programme has consisted of a standard care protocol and an annual reporting system, and predialysis modality education was established as part of the programme in 2003. The programme's availability extended rapidly across the country, and it was available in $19(4.1 \%)$ hospitals in 2005 and in $126(22.1 \%)$ hospitals by the end of 2011. ${ }^{15}$ The results from a Taiwanese prospective controlled cohort study showed that this programme delayed dialysis initiation, improved first-year dialysis survival, and that it might increase the likelihood of selecting PD as the treatment modality. ${ }^{16}$ Based on the results from this prospective study, the Bureau of NHI in Taiwan executed mandatory dialysis modality selection education for all patients on dialysis before they began long-term dialysis in 2005.

\section{Increasing the PD incidence as a KPI for hospital accreditation}

Hospital accreditation, which requires supervision by the Taiwan Joint Commission on Hospital Accreditation (TJCHA) every year, began in Taiwan in 1978. The TJCHA now includes revised accreditation standards, survey methods and a surveillance system to evaluate the 
entire patient care process to improve quality and safety. Fulfilling the accreditation requirements is essential for hospitals in Taiwan to be able to participate in the NHI programme. NHI payments are reduced if hospitals do not achieve accreditation, and additional hospital downgrades may occur. In 2006, a scheme was implemented in hospitals that involved using increasing the PD incidence as a KPI for hospital accreditation. The KPI accreditation scheme was modified in 2010 to stipulate that the number of new patients on PD must exceed the number of new patients on HD by $9 \%$ in an accredited hospital.

\section{Reimbursement of the glucose-free dialysate, icodextrin}

Glucose-free dialysate is considered beneficial in PD management, ${ }^{17}$ and it was introduced in Taiwan in early 2000. However, the Bureau of NHI in Taiwan limited its use by conducting inspections before use because of its high cost, which led to the infrequent use of glucosefree dialysate. In 2007, the Bureau of NHI announced that glucose-free dialysate would be reimbursed to encourage PD. This policy clearly indicated that patients with a high/high average score on the peritoneal equilibrium test, poor ultrafiltration, which was defined as using more than two bags of $2.5 \%$ and $4.25 \%$ dialysate to achieve adequate ultrafiltration, and diabetes that was characterised by poor glucose control, which was defined as a glycated haemoglobin level $>7 \%$, could use icodextrin or glucose-free dialysate, which increased its use.

\section{Insurance reimbursement for renting APD machines}

APD machines offer several advantages in relation to the quality of patient's lives and clinical outcomes of patients on PD. ${ }^{18}$ The high cost associated with renting an APD machine may have limited its uptake. To solve this problem, the Bureau of NHI in Taiwan has covered the cost of renting APD machines since 2008.

\section{Statistical analysis}

This study's primary outcome was the PD incidence during each year of the study period. The PD incidence was further stratified according to age, sex and a history of diabetes mellitus. The descriptive statistics are expressed as the means (SDs), medians (ranges) or frequencies (percentages). The data were analysed using SPSS software, V.17.0 for Windows XP (SPSS, Chicago, Illinois, USA).

\section{RESULTS}

PD incidence trend according to the timing of the four major health policies

By 31 December 2009, 539 HD and 113 PD units had been established in Taiwan, and compared with December 2005, there were 78 more HD units and 54 more PD units. During this period, the rate at which the number of PD units increased $(91.5 \%)$ was higher than the rate at which the number of HD units increased $(16.9 \%)$. The proportion of multidisciplinary predialysis care programme-certified hospitals increased from $9.5 \%$ $(44 / 461)$ in 2006 to $15.4 \%(78 / 507)$ in 2008 and to $22.1 \%(126 / 569)$ in 2011. APD machine use among the patients on PD increased from $10.1 \%(326 / 3237)$ in 2005 to $20.1 \%(939 / 4682)$ in 2009 , and icodextrin PD fluid uptake increased from $5.9 \%$ in 2005 to $47.9 \%$ in 2009 (figure 1), which was the highest rate compared with the nearby countries. The reimbursement of icodextrin dialysate might have encouraged nephrologists to use icodextrin dialysate rather than traditional glucose-based dialysates in patients on PD with refractory fluid overloads, but this policy was associated with a limited increase in the PD incidence (figure 1). From 2007 to 2008, the PD incidence did not increase. The number of APD machines rented slowly increased before 2008. After the insurance reimbursement for APD machine rental was initiated in 2008, APD machine use increased faster than the PD incidence (figure 1). Reimbursing the APD machine rental costs and the icodextrin dialysate costs had weak associations with the PD incidence as shown in figure 1. Figure 2 depicts the PD usage rate from 2006 to 2013. After a steady increase in the PD usage rate from 2006 to 2009, it declined. In 2006, increasing the PD incidence became a KPI for hospital accreditation. Consequently, many hospitals had initiated PD programmes from 2006. We observed that from 2006 to 2009, the rate at which the number of PD units increased $(91.5 \%)$ was higher than the rate at which the number of HD units increased (16.9\%). Figure 3 illustrates the relationships between the PD incidence and the health policies based on the data from the TWRDS from 2006 to 2013. The PD incidence rose dramatically in 2007 and it remained stable until 2009. The two policies (multidisciplinary predialysis care programme and using increasing the PD incidence as a KPI for hospital accreditation) that were implemented in 2006 were associated with increases in the PD incidence. The subsequent withdrawal of the policy that used an increase in the PD incidence as a KPI for hospital accreditation in 2010 was associated with a fall in PD incidence to a level that was below that in 2006. The policies that were implemented in 2007 and 2008, namely the reimbursement of icodextrin dialysate costs and the reimbursement of APD machine rental costs, respectively, were not associated with increases in PD use.

\section{PD incidence trend from 2006 to 2013 stratified according to the age intervals in the TWRDS}

The mean age of the patients on HD who participated in this study was 64.7 (13.7) years, which was nearly 10 years older than that of the patients on PD who participated in this study (54.6 (15.7) years). Table 1 shows the HD and PD incidence from 2006 to 2013 based on the TWRDS data. In 2006, $45.2 \%$ of the study population comprised patients aged $>65$ years. In $2013,54.1 \%$ of the study population comprised patients aged 


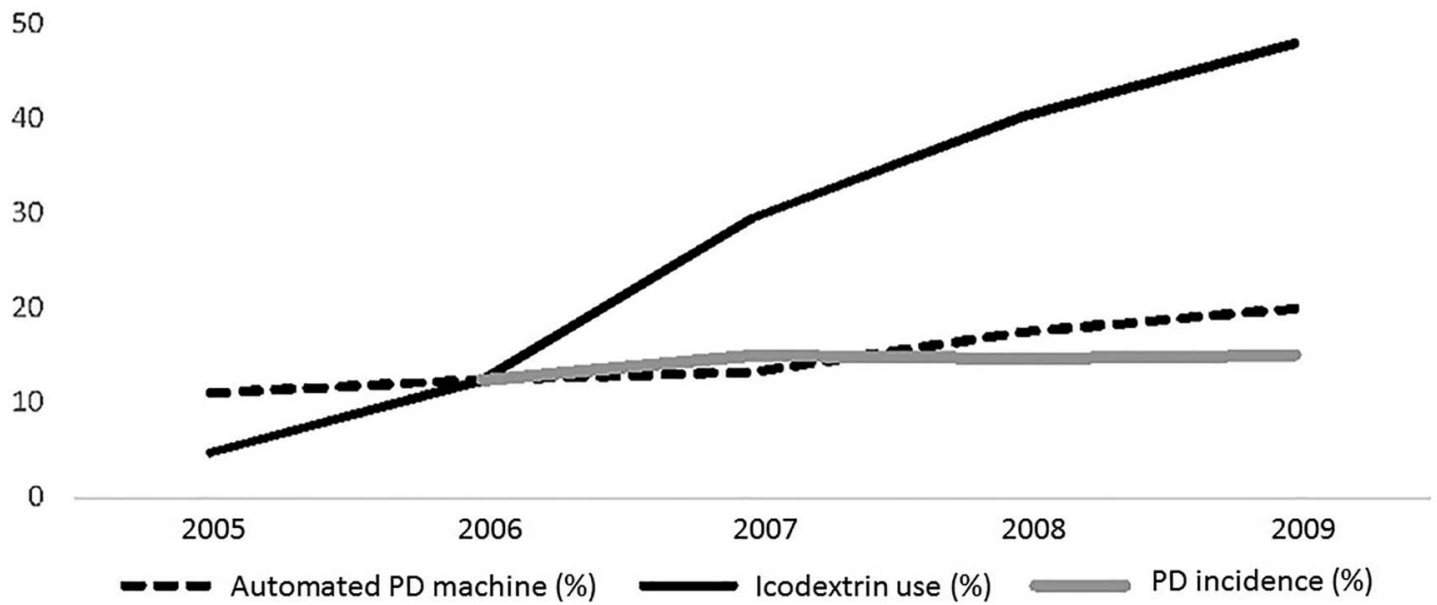

Figure 1 The relationships between APD machine use and icodextrin dialysate use and PD incidence. APD, automated peritoneal dialysis; PD, peritoneal dialysis.

Figure 2 PD incidence from 2006 to 2013 based on the Taiwan Renal Registry Data System data. PD, peritoneal dialysis.

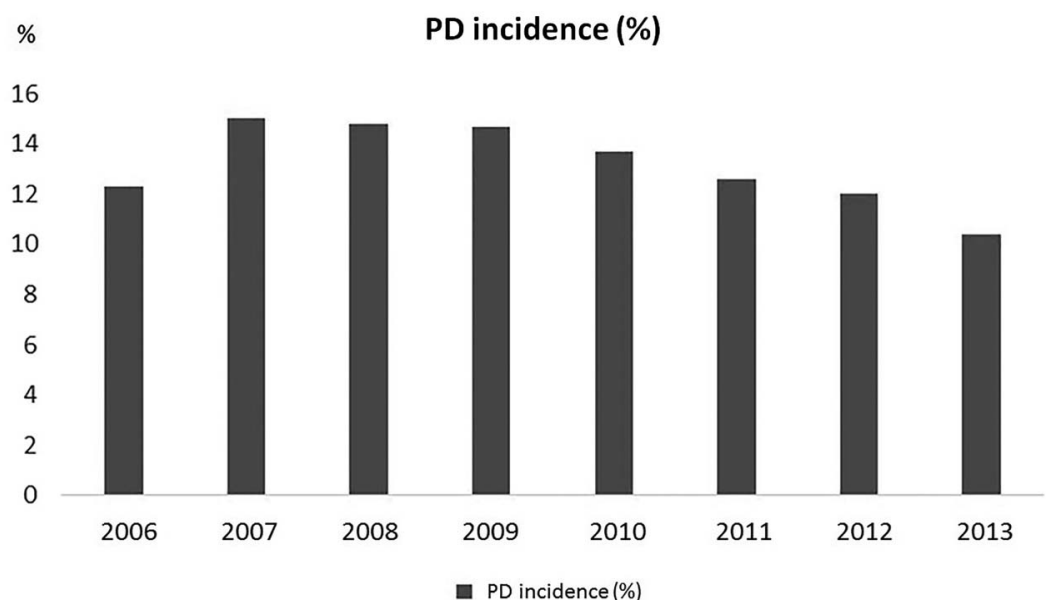

$>65$ years. Therefore, the mean age of the patients undergoing dialysis increased between 2006 and 2013.

PD incidence trend according to the presence of diabetes stratified according to the age of $\mathbf{6 0}$ years

Table 2 presents the data obtained from the TWRDS from 2006 to 2013. Female patients with ESRD had a higher PD incidence than male patients. Similar percentages of patients with uraemia and diabetes selected PD from 2006 to 2013 . When the data were stratified according to the presence of diabetes and being aged $>60$ years, a much lower incident PD percentage was evident among patients with ESRD who were aged $>60$ years and had diabetes.

\section{DISCUSSION}

This study's main finding demonstrated that implementing the four PD promotional policies was associated with increases in the PD incidence, while repealing the policy that using increasing the PD incidence as a KPI for hospital accreditation was associated with a decline in the PD incidence. The findings from a study by Vonesh and Moran $^{19}$ that used data from the USRDS showed that the PD:HD death rate was strongly correlated with a patient's age, sex and the presence of diabetes mellitus. This affects the willingness of physicians and patients to use PD as RRT, especially when the patients are old or have diabetes. The analysis of the information in the TWRDS showed that the patients on PD were almost 10 years younger than the patients on HD, and that there was a slight predominance of women. However, there were no obvious changes with respect to the patients' ages and sexes, and the presence of diabetes mellitus during the study period. Moreover, health policy or medical reimbursement provisions, including copayment policies for outpatients and the selection of hospital, ${ }^{20}$ may have influenced accessibility to 
Figure 3 PD incidence from 2006 to 2013 based on the Taiwan Renal Registry Data System data and health policy timing. PD, peritoneal dialysis.
PD incidence (\%)

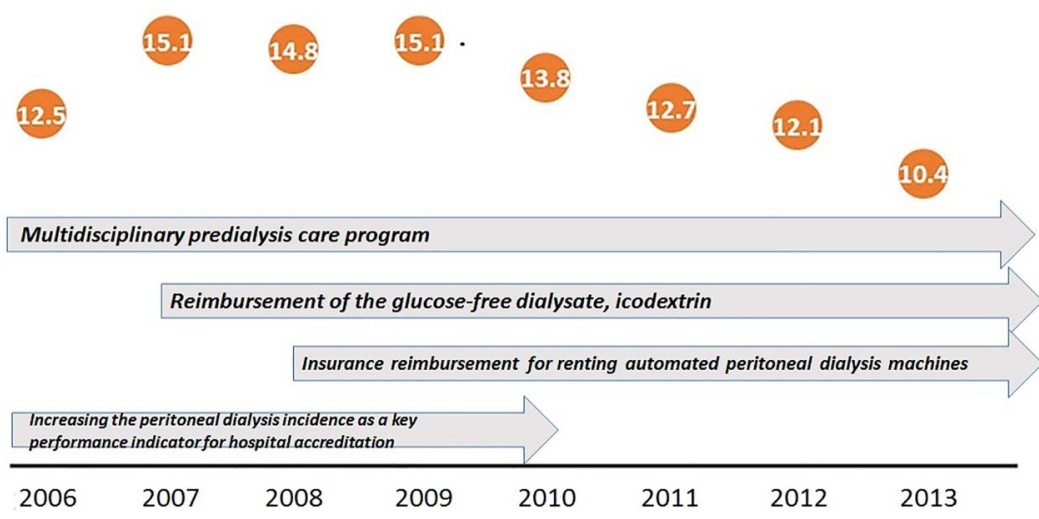

Table 1 Annual number and percentage of incident HD and PD stratified by age groups from 2006 to 2013

\begin{tabular}{|c|c|c|c|c|c|c|c|c|c|c|c|c|c|c|c|c|}
\hline \multirow{2}{*}{$\begin{array}{l}\text { Year } \\
\text { Group }\end{array}$} & \multicolumn{2}{|l|}{2006} & \multicolumn{2}{|l|}{2007} & \multicolumn{2}{|l|}{2008} & \multicolumn{2}{|l|}{2009} & \multicolumn{2}{|l|}{2010} & \multicolumn{2}{|l|}{2011} & \multicolumn{2}{|l|}{2012} & \multicolumn{2}{|l|}{2013} \\
\hline & HD & PD & HD & PD & HD & PD & HD & PD & HD & PD & HD & PD & HD & PD & HD & PD \\
\hline$<45$ years & 692 & 337 & 645 & 353 & 671 & 366 & 641 & 341 & 674 & 362 & 690 & 343 & 705 & 288 & 806 & 90 \\
\hline 45-64 years & 3206 & 478 & 2927 & 606 & 3115 & 645 & 2897 & 605 & 3195 & 616 & 3371 & 594 & 3487 & 600 & 3553 & 412 \\
\hline$\geq 65$ years & 3643 & 245 & 3733 & 333 & 4250 & 385 & 3860 & 367 & 4418 & 342 & 4364 & 279 & 4533 & 293 & 5227 & 502 \\
\hline Total (\%) & 87.5 & 12.5 & 84.9 & 15.1 & 85.2 & 14.8 & 84.9 & 15.1 & 86.2 & 13.8 & 87.3 & 12.7 & 87.9 & 12.1 & 89.6 & 10.4 \\
\hline $\begin{array}{l}\text { Mean (SD) } \\
\text { age (years) }\end{array}$ & $\begin{array}{l}63 \\
(14)\end{array}$ & $\begin{array}{l}51 \\
(17)\end{array}$ & $\begin{array}{l}63 \\
(14)\end{array}$ & $\begin{array}{l}53 \\
(16)\end{array}$ & $\begin{array}{l}64 \\
(14)\end{array}$ & $\begin{array}{l}54 \\
(17)\end{array}$ & $\begin{array}{l}64 \\
(14)\end{array}$ & $\begin{array}{l}54 \\
(17)\end{array}$ & $\begin{array}{l}64 \\
(14)\end{array}$ & $\begin{array}{l}53 \\
(16)\end{array}$ & $\begin{array}{l}64 \\
(15)\end{array}$ & $\begin{array}{l}53 \\
(16)\end{array}$ & $\begin{array}{l}64 \\
(15)\end{array}$ & $\begin{array}{l}54 \\
(16)\end{array}$ & $\begin{array}{l}64 \\
(15)\end{array}$ & $\begin{array}{l}54 \\
(16)\end{array}$ \\
\hline
\end{tabular}

$\mathrm{HD}$, haemodialysis; PD, peritoneal dialysis.

Table 2 Annual percentage of incident PD according to sex, the presence of diabetes mellitus and being aged $>60$ from 2006 to 2013

\begin{tabular}{lrrrrrrrr}
\hline Group/year & $\mathbf{2 0 0 6}$ & $\mathbf{2 0 0 7}$ & $\mathbf{2 0 0 8}$ & $\mathbf{2 0 0 9}$ & $\mathbf{2 0 1 0}$ & $\mathbf{2 0 1 1}$ & $\mathbf{2 0 1 2}$ & $\mathbf{2 0 1 3}$ \\
\hline Male (\%) & 47.5 & 46.9 & 47.6 & 48.2 & 46.7 & 46.4 & 46.7 & 49.0 \\
Female (\%) & 52.5 & 53.1 & 52.4 & 51.8 & 53.3 & 53.6 & 53.3 & 51.0 \\
DM (\%) & 43.2 & 43.9 & 46.2 & 46.0 & 45.2 & 45.9 & 45.7 & 45.0 \\
Older patients with DM (>60 years) (\%) & 5.5 & 6.8 & 7.3 & 7.6 & 7.2 & 6.2 & 5.2 & 5.8 \\
\hline DM, diabetes mellitus; PD, peritoneal dialysis. & & & & &
\end{tabular}

appropriate medical treatment. The regulation of or a lack of freedom to choose PD may negatively impact on the quality of patients' lives. ${ }^{21}$ Although individual physicians have experience and their personal preferences, a patient who is eligible for PD and HD has complete access to either dialysis modality in Taiwan. Physician and care provider incentives and reimbursements for HD are similar to those for PD, for example, physicians' fees amount to US $\$ 120 / \mathrm{HD}$ patient per month and they are up to US $\$ 100 / \mathrm{PD}$ patient per month, and the insurance payments to healthcare institutions are also comparable at US $\$ 1600 / \mathrm{HD}$ patient per month and up to US $\$ 1600 / \mathrm{PD}$ patient per month; these may vary because of the different PD dialysate doses and the different administration modalities, namely APD machines or continuous ambulatory PD.

Of the four policies that were implemented, the multidisciplinary predialysis care programme might have been associated with increases in the selection of PD by patients with uraemia, because PD has the advantages of being home-based therapy and using convenient equipment, and it saves time compared with HD. Multidisciplinary care was implemented in the Taiwanese predialysis care programme, and a large cohort study that investigated multidisciplinary care in Taiwan reported a greater willingness among patients with ESRD to select PD. ${ }^{22}$ According to the providers, younger patients who have residual renal function tend to be more suitable candidates for $\mathrm{PD} ;{ }^{23}$ therefore, patients on PD may be almost 10 years younger than patients on $\mathrm{HD}$.

The provision of full insurance coverage for APD machine rental since 2008 was associated with a substantial effect on decisions of patients on dialysis regarding APD machine rental. In addition, patients who used APD machines had a lower peritonitis rate. ${ }^{24}$ The implementation of an APD machine rental reimbursement 
policy in China may have influenced the ESRD survival rate or reduced the rate of technique failure among young Chinese patients. ${ }^{12}$ In addition, the reimbursement of the costs associated with the use of icodextrin dialysate in Taiwan since 2007 may have influenced the PD usage rate by reducing mortality and the PD patient dropout rate. ${ }^{25}$ However, the results from our study only indicated weak associations between these policies and the PD incidence, suggesting that these policies had much less critical roles.

Hospital accreditation inspections by the TJCHA were initiated by the government in 1999, and 12 of the healthcare organisations in Taiwan had attained a Gold Seal of Approval as Joint Commission Internationalaccredited entities by 2011 for achieving patient-centred care. ${ }^{26}$ Hospital accreditation affects hospital grading, as well as affects reimbursements from the Bureau of NHI. Increasing the incidence of PD was used as a KPI for hospital accreditation, and it may have been associated with an increase in the PD usage rate. Insurance reimbursements for APD machine rental and icodextrin dialysate were the most potent factors that stimulated PD usage among providers and hospitals in the USA. ${ }^{27}$ However, the reduction in the PD incidence since 2010 in Taiwan was strongly associated with the accreditation requirement revisions that took place in 2010. This new policy lowered the threshold for achieving favourable KPI scores, which may have influenced the willingness of healthcare providers to promote PD as a dialysis modality despite the continuation of the reimbursements for APD machine rental and icodextrin dialysate, which is indicative of the critical importance of this policy

From the patient's perspective, the convenience of therapy is as important as its efficacy, and PD is a homebased therapy that saves time. However, the number of HD sites is far higher than the number of PD sites in Taiwan, which provides a strong ESRD care network, particularly in urban areas. Nevertheless, from 2005 to 2009, the number of new PD facilities was higher than the number of new HD facilities. In addition, the Bureau of NHI provided complete reimbursements for PD facilities and physicians, and for PD catheters and medical expenses of patients on PD. Co-pay for patients in PD or HD did not change either.

This study has some limitations that are described next. First, this was a retrospective study that did not include valid laboratory data or dialysis quality assessments. However, the study's data were obtained from the TWRDS, which was the largest ESRD database in Taiwan at the time. Second, this study only presented the timings of the PD promotional policies and the incidence of PD, which did not prove causation. Third, valid kidney transplant records were missing from the database.

Currently, it is mandatory to undertake CKD prevention and quality improvement programmes in Taiwan. Future investigations should estimate the survival of the patients on dialysis whose data were analysed in this study and it should be assessed whether the KPI that was associated with the promotion of PD incidence could be extended to improve ESRD outcomes. Other issues to be investigated should include financial incentives and the promotion of low-cost dialysis modalities. ${ }^{28}$

\section{CONCLUSIONS}

Of the four health policies that were intended to increase the PD incidence, using increasing the PD incidence as a KPI for hospital accreditation appeared to have the strongest association.

Acknowledgements The authors would like to thank Kuang-wen Wang for analytical assistance and Yi-Jiun Chen and Huey-May Lin for their secretarial assistance.

Contributors Yi-CL, Ye-CL and M-SW conceived and designed the experiments; $\mathrm{Yi}-\mathrm{CL}$ performed the experiments; $\mathrm{Ye}-\mathrm{CL}$ and $\mathrm{C}-\mathrm{CH}$ analysed the data; $\mathrm{Yi}-\mathrm{CL}, \mathrm{H}-\mathrm{HC}$ and $\mathrm{C}-\mathrm{CK}$ contributed reagents/materials/analysis tools; $\mathrm{Yi}-\mathrm{CL}$ and $\mathrm{M}-\mathrm{SW}$ wrote the manuscript.

Funding This research received no specific grant from any funding agency in the public, commercial or not-for-profit sectors.

\section{Competing interests None declared.}

Ethics approval Taipei Medical University Institutional Review Board Ethics Committee (No. 201405054)

Provenance and peer review Not commissioned; externally peer reviewed.

Data sharing statement No additional data are available.

Open Access This is an Open Access article distributed in accordance with the Creative Commons Attribution Non Commercial (CC BY-NC 4.0) license, which permits others to distribute, remix, adapt, build upon this work noncommercially, and license their derivative works on different terms, provided the original work is properly cited and the use is non-commercial. See: http:// creativecommons.org/licenses/by-nc/4.0/

\section{REFERENCES}

1. Foley RN, Collins AJ. The USRDS: what you need to know about what it can and can't tell us about ESRD. Clin J Am Soc Nephrol 2013;8:845-51.

2. Oh KH, Kim YL, Lo WK, et al. Peritoneal dialysis-moving from current status to the future. Int J Nephrol 2013;2013:530713.

3. Blake PG. Integrated end-stage renal disease care: the role of peritoneal dialysis. Nephrol Dial Transplant 2001;16(Suppl 5):61-6

4. Jha V. Peritoneal dialysis in India: current status and challenges. Perit Dial Int 2008;28(Suppl 3):S36-41.

5. Dhanakijcharoen P, Sirivongs D, Aruyapitipan S, et al. The "PD First" policy in Thailand: three-years experiences (2008-2011). J Med Assoc Thai 2011;94(Suppl 4):S153-61.

6. Yu AW, Chau KF, Ho YW, et al. Development of the "peritoneal dialysis first" model in Hong Kong. Perit Dial Int 2007;27(Suppl 2): S53-5.

7. Li PK, Chow KM. Peritoneal dialysis-first policy made successful: perspectives and actions. Am J Kidney Dis 2013;62:993-1005.

8. Mehrotra R, Devuyst O, Davies SJ, et al. The current state of peritoneal dialysis. J Am Soc Nephrol 2016;27:3238-52.

9. World Medical A. World Medical Association Declaration of Helsinki: ethical principles for medical research involving human subjects. JAMA 2013;310:2191-4.

10. Yang WC, Hwang SJ. Incidence, prevalence and mortality trends of dialysis end-stage renal disease in Taiwan from 1990 to 2001: the impact of national health insurance. Nephrol Dial Transplant 2008;23:3977-82.

11. Hwang SJ, Lin MY, Chen $\mathrm{HC}$, et al. Increased risk of mortality in the elderly population with late-stage chronic kidney disease: a cohort study in Taiwan. Nephrol Dial Transplant 2008;23:3192-8.

12. Huang CC, Cheng KF, Wu HD. Survival analysis: comparing peritoneal dialysis and hemodialysis in Taiwan. Perit Dial Int 2008;28 (Suppl 3):S15-20.

13. Hwang SJ, Yang WC, Lin MY, et al. Impact of the clinical conditions at dialysis initiation on mortality in incident haemodialysis patients: 
a national cohort study in Taiwan. Nephrol Dial Transplant 2010;25:2616-24.

14. Hwang SJ, Tsai JC, Chen HC. Epidemiology, impact and preventive care of chronic kidney disease in Taiwan. Nephrology (Carlton) 2010;15(Suppl 2):3-9.

15. Wu M, Wu I, Hsu K. Survival analysis of Taiwan Renal Registry Data System (TWRDS) 2000-2009. Acta Nephrologica 2012;26:104-8.

16. Wu IW, Wang SY, Hsu KH, et al. Multidisciplinary predialysis education decreases the incidence of dialysis and reduces mortality - a controlled cohort study based on the NKF/DOQI guidelines. Nephrol Dial Transplant 2009;24:3426-33.

17. Cho Y, Johnson DW, Badve S, et al. Impact of icodextrin on clinical outcomes in peritoneal dialysis: a systematic review of randomized controlled trials. Nephrol Dial Transplant 2013;28:1899-907.

18. Sun CY, Lee CC, Lin YY, et al. In younger dialysis patients, automated peritoneal dialysis is associated with better long-term patient and technique survival than is continuous ambulatory peritoneal dialysis. Perit Dial Int 2011;31:301-7.

19. Vonesh EF, Moran J. Mortality in end-stage renal disease: a reassessment of differences between patients treated with hemodialysis and peritoneal dialysis. J Am Soc Nephrol 1999;10:354-65.

20. Chen LC, Schafheutle EI, Noyce PR. The impact of nonreferral outpatient co-payment on medical care utilization and expenditures in Taiwan. Res Social Adm Pharm 2009;5:211-24.
21. Szabo E, Moody H, Hamilton $\mathrm{T}$, et al. Choice of treatment improves quality of life. A study on patients undergoing dialysis. Arch Intern Med 1997;157:1352-6.

22. Chen YR, Yang Y, Wang SC, et al. Effectiveness of multidisciplinary care for chronic kidney disease in Taiwan: a 3-year prospective cohort study. Nephrol Dial Transplant 2013;28:671-82.

23. Goodlad C, Brown E. The role of peritoneal dialysis in modern renal replacement therapy. Postgrad Med J 2013;89:584-90.

24. Huang JW, Hung KY, Yen CJ, et al. Comparison of infectious complications in peritoneal dialysis patients using either a twin-bag system or automated peritoneal dialysis. Nephrol Dial Transplant 2001;16:604-7.

25. Kuriyama R, Tranaeus A, Ikegami T. Icodextrin reduces mortality and the drop-out rate in Japanese peritoneal dialysis patients. Adv Perit Dial 2006;22:108-10.

26. Ryan C. The Power to drive change: working together for excellence. Creating a continuously improving consumer engagement framework for excellence in patient-centered care. World Hosp Health Serv 2016;52:37-41.

27. Burkart J. The future of peritoneal dialysis in the United States: optimizing its use. Clin J Am Soc Nephrol 2009;4(Suppl 1): S125-31.

28. Cleemput I, De Laet C. Analysis of the costs of dialysis and the effects of an incentive mechanism for low-cost dialysis modalities. Health Policy 2013;110:172-9. 